\title{
A Clinical Review of Adult Paraplegic Patients with Complete Lesions Using the ORLAU ParaWalker
}

\author{
P. Moore, MCSP, ONC, J. Stallard, BTech, CEng, MIMechE \\ Orthotic Research E Locomotor Assessment Unit, The Robert Fones E Agnes Hunt \\ Orthopaedic Hospital, Oswestry SY10 7AG, UK.
}

\begin{abstract}
Summary
A clinical review of 50 adult patients with high level complete spinal lesions, for whom the ORLAU ParaWalker had been prescribed, was undertaken at routine clinical follow-up visits using a questionnaire. The patients had an average age of 31.7 years, an average weight of $68.8 \mathrm{~kg}$, an average height of $1.74 \mathrm{~m}$ and $78 \%$ had a complete lesion at T9 or above. With an average follow-up period of 34.4 months (min 7 months), $64 \%$ were continuing to use the device on a regular basis and more than $78 \%$ of those who responded had achieved complete independence. Analysis of the results provides further evidence that the ORLAU ParaWalker is a clinically viable routine treatment for appropriate paraplegic patients with complete mid-thoracic lesions. The need for more precise clinical criteria to further improve the rate of long term use was identified.
\end{abstract}

Key Words: Paraplegia; Spinal injury; ParaWalker; Walking

The ORLAU ParaWalker (originally known as Hip Guidance Orthosis (HGO)), which permits paraplegic patients to walk reciprocally with crutches, was introduced in 1975 for spina bifida children (Rose, 1979; Rose et al., 1981). It was first used for adult patients in 1981 and at that time it was not known how well the principles which had been successfully applied to children would translate to heavier, taller subjects with complete thoracic lesions. Initial results were very encouraging and this led to a programme of research and development. Experience in clinical trials with selected patients enabled a number of important modifications to the mechanical design and the treatment system to be introduced (Stallard et al., 1986). By 1985, the ParaWalker was being routinely supplied in Oswestry to adult patients who were considered suitable. Thereafter, monitoring of these patients became a routine rather than research procedure as they fitted into the pattern established for children at 6-monthly clinical review. When, in 1986, the DHSS commissioned ORLAU to undertake a 3-year training programme for centres wishing to supply the ParaWalker (ORLAU 1986), the standard course featured supply to both children and adults.

Since the concept of ambulation for a significant proportion of adults with 
complete thoracic lesions was new, some concern was felt about the prospects for long term use of the device by such patients. Several studies on the provision of ambulation orthoses have shown that they are abandoned within a few months in a high proportion of cases (Hahn, 1974; Rosman and Spira, 1974; Mikelberg and Reid, 1981). Other anecdotal evidence from Spinal Injuries Units suggests that for complete thoracic paraplegic patients (the ParaWalker target group) very few continue to use conventional calipers beyond 6 months after prescription. With those concerns in mind, and with the experience of greatly improved ambulation performance of patients using the ParaWalker, the Midlands Spinal Injuries Unit undertook a review of the first 20 adult ParaWalker patients (Summers et al., 1988). Their findings were very encouraging in that $85 \%$ of these continued to use the orthosis with an average follow-up of 20 months. However, it was recognised that a significant proportion of the patients involved were probably more selectively chosen for research purposes and more highly motivated because of their research involvement than those who are routinely supplied, and that this was likely to give a favourable bias to the results. Because of this a second study on all adult patients routinely supplied in Oswestry was undertaken in 1988 via the standard 6-monthly clinical review of ParaWalker patients.

\section{Patients and methods}

Fifty patients with complete lesions ranging from L1 to T3 and who had used the ParaWalker for a minimum of 6 months were identified. These were the first adults supplied by ORLAU apart from 8 patients who later transferred to other ParaWalker Centres for their own convenience. Arrangements were made for interviews to be conducted at their next routine clinical appointment by people not associated with supply of the orthosis. Those patients who failed to keep an appointment were contacted by telephone. These interviews were carried out at length and were no less rigorous than those done by direct interview. Neurological levels of lesion were confirmed by fully trained doctors. Those patients from whom no response was received were classified as being non-users.

\section{Results}

The interview elicited the following information from each of the 50 patients:

$\begin{array}{ll}\text { Sex } & -42 \text { Male } 8 \text { Female } \\ \text { Age } & -22 \text { years }-53 \text { years } \\ & \text { Average } 31.7 \\ \text { Weight } & \text { Avg- } 94.4 \mathrm{~kg} \\ & \text { Average } 68.8 \mathrm{~kg} \\ \text { Height } & 1.52 \mathrm{~m}-1.93 \mathrm{~m} \\ \text { Time since supply } & \text { Average } 1.74 \mathrm{~m} \\ \text { of ParaWalker } & -7 \text { months }-87 \text { months } \\ \text { Time from injury } & -3 \text { months }-268 \text { months } \\ \text { to supply of } & \text { Average } 62 \text { months } \\ \text { ParaWalker } & \end{array}$


Level of Lesion Distribution

\begin{tabular}{cc} 
Level (complete) & No. of Patients \\
T3 & 1 \\
T4 & 14 \\
T5 & 4 \\
T6 & 5 \\
T7 & 7 \\
T8 & 4 \\
T9 & 4 \\
T10 & 3 \\
T11 & 3 \\
T12 & 1 \\
L1 & 4 \\
\hline
\end{tabular}

For the patients who did not respond the preceding information was recorded directly from the notes.

In addition standard questions were asked of each patient and the following information was ascertained:

1. Is the ParaWalker still used on a regular basis?
32 YES
$14 \mathrm{NO}$
4 NO CONTACT

2. Is (or was) the ParaWalker used outdoors ( $50 \mathrm{~m}$ from the house)? 30 YES

$\begin{array}{lc}\quad \text { Total Distance } & \text { No. of Patients } \\ \text { Under } 100 \mathrm{~m} & 12 \\ 200-300 \mathrm{~m} & 3 \\ \frac{1}{4} \text { mile } & 4 \\ \frac{1}{2} \text { mile } & 7 \\ 1 \text { mile } & 4\end{array}$

3. Is (or was) the patient fully independent (i.e. put on, take off orthosis, rise to standing and descend to seat without assistance)?
36 YES
$10 \mathrm{NO}$
4 NO CONTACT

Two of the 10 only recorded 'no' because they were unable to secure knee locks because of spasm. Three of the remaining 8 had given up using the ParaWalker.

4. Is the patient able to use a car whilst wearing the ParaWalker?

$\begin{array}{lll}\text { As a passenger } & 20 \mathrm{YES} & 26 \mathrm{NO} \\ \text { As a driver } & 14 \mathrm{YES} & 32 \mathrm{NO}\end{array}$

5. On how many days does (or did) the patient use the ParaWalker each week?

$\begin{array}{cc}\text { Days per week } & \text { No. of patients } \\ 7 & 8 \\ 5-6 & 4 \\ 3-4 & 11 \\ 1-2 & 18 \\ \text { less than } 1 & 5\end{array}$

6. For how long does (or did) the patient use the ParaWalker on each occasion? 


$\begin{array}{cc}\text { No. of hours } & \text { No. of patients } \\ 2-3 & 6 \\ 1 \frac{1}{2}-2 & 14 \\ 1 & 18 \\ \text { less than } 1 & 8\end{array}$

7. What is (or was) the patient's own assessment of use of the ParaWalker?

$\begin{array}{lc}\text { Patient assessment } & \text { No. of patients } \\ \text { Highly delighted } & 11 \\ \text { Pleased } & 26 \\ \text { Non Committal } & 5 \text { (3 gave up) } \\ \text { Dislike } & 4 \text { (4 gave up) }\end{array}$

8. What has the ParaWalker been used for other than therapeutic or leisure exercise?

\section{Activity}

Play darts

Play pool

To get married

To receive a presentation

To stand at the bar

DIY (limited)

Car maintenance

To stand and chat

To stand

No. of patients
1
1
2
1
1
1
2
1
1

\section{Discussion}

This study was prompted by the Summers et al. (1988) review of the first 20 adult ParaWalker patients which produced encouraging results with an average followup period of 20 months. It was recognised that the high proportion of patients in this review still using the device $(85 \%)$ could be interpreted as more a reflection of the commitment of the earlier 'pioneer' users who might be expected to continue using the device enthusiastically, than as evidence of genuine improvement in ease of ambulation in a true clinical context. What has emerged from this study is that the Summers et al. (1988) review findings were only marginally influenced by 'pioneers', and that the relative ease of ambulation in the ParaWalker permits a wider range of patients than was originally envisaged to be practical.

The age range of the patients in the Review was wider than expected with patients in their 40s and 50s successfully using the ParaWalker. Whilst the average age of 31.7 years indicates a predominance of younger people it was considered important that the device is not exclusively used by younger age groups.

Only $16 \%$ of the patients in the review were female. This is undoubtedly a reflection of the lower numbers of females sustaining spinal injury, but it has been suggested by some clinicians that it may also be influenced by a difference between the sexes in attitude to walking and cosmesis.

The time from injury to supply of the ParaWalker varied from 3 to 268 months, with an average of 62 months. This shows that it is not necessary to take a patient 
soon after injury in order to achieve success, though ORLAU is still of the opinion that being an independent wheelchair user is one of the important pre-requirements for prescription.

The time of review follow-up after supply of the ParaWalker varied from 7 to 87 months with an average of 34.4 months. This is a significantly longer followup than the Summers et al. (1988) review and covers more than twice as many ParaWalker patients. Not surprisingly the proportion of patients continuing to use the device has dropped a little. However, that this only reduced to $64 \%$ is greatly encouraging when the factors which can contribute to this reduction are considered. These include a lower level of direct commitment through being routine rather than 'research' patients, a longer period in which medical factors can intervene, disenchantment or change of circumstances, and a less strict selection policy. That patients in the mid-thoracic complete lesion target group were most commonly supplied is evidenced by the fact that $78 \%$ had a lesion at T9 or above.

There are few papers published on bracing in this target group. Hahn (1969) reviewed complete lesion patients at $\mathrm{L} 1$ or above using a fixed ankle KAFO design. Of the 52 patients who answered his questionnaire $63 \%$ were below $\mathrm{T} 9$ and are therefore of a generally lower level. The follow-up period varied from less than 1 year to greater than 4 years and had an average of approximately 2 years. Only $50 \%$ of those who responded were able to walk 'solo'. If a similar analysis is conducted on the ORLAU patients, the figure for continued usage rises to $70 \%$, with higher levels of lesion and a longer average follow-up. Using the same approach adopted in the ORLAU Review, where no response was interpreted as the patient having abandoned the orthosis, the Hahn review result would reduce to $35 \%$ of patients walking independently.

Rosman and Spira (1974) reported that paraplegic patients with complete lesions between $\mathrm{T} 1$ and $\mathrm{T} 6$ were found not to use their orthoses at all and those with lesions at T7-T11 used orthoses for standing purposes only. Mikelberg and Reid (1984) in a review of a whole range of spinal cord lesion patients of 15 years of age and older showed that for 12 complete thoracic lesion patients (4 T5-T7 and 8 T12-L1) using bilateral calipers and 9 incomplete lesions from $\mathrm{C} 7$ to cauda equina ( 3 of whom had one long leg and one short leg brace) only $45 \%$ continued to use their orthoses. The follow-up period varied from 1 to 6 years, but no information was given on the distribution of the timespan.

Clearly the ParaWalker achieves a significantly greater proportion of long term independent usage for complete thoracic lesion patients than other orthoses have achieved. This is despite the average follow-up period being longer, the average level of lesion being higher, and the inclusion of incomplete lesions in some reviews.

The great majority of ParaWalker patients maintained the ability to be completely independent, with more than $78 \%$ of those who responded to the question being able to doff, don and transfer. Two of those not independent only failed to achieve this because they had difficulty in overcoming spasm to lock the knee joint. The high percentage of those achieving independence emphasises the importance of this facility to long term use of ambulatory orthoses.

Of the 46 patients in the ORLAU Review who answered the questionnaire 20 were able to wear the orthosis as a passenger in a car, but only 14 were able to drive. The inability to abduct when wearing the ParaWalker creates difficulties 
for transfer into a car and it is only possible in models which have good access.

The patients' own assessment of the ParaWalker was almost identical to that recorded in the Summers review, with $80 \%$ indicating that they were either Highly Delighted (24\%) or Pleased (56\%). Of the 4 patients who were 'non-commital' 3 gave up the ParaWalker and the 4 patients who 'disliked the device' all gave up using it.

Although the ParaWalker is primarily used as a therapeutic and social device, $20 \%$ of patients reported that it had some functional value. Most interesting amongst the functional activities include getting married, car maintenance, DIY and sport.

The review by Summers et al. (1988) showed that the ParaWalker had enabled new levels of patient acceptance for paraplegic walking orthoses to be achieved. This review sought to repeat the essential features of that research, but with a longer follow-up on a wider range of patients so that potential bias through the use of highly motivated 'research' patients could be minimised. These results, when taken in conjunction with the study of the energy cost of walking (Nene, 1989) in which it was shown that the efficiency of ambulation for mid-thoracic lesion patients was significantly greater for the ParaWalker than long-leg calipers, further reinforces the viability of the device as a long term treatment for appropriate thoracic lesion paraplegic patients. That $64 \%$ continue to use it in a long term follow-up should allay the scepticism of those who feel it merely has novelty value for the majority of patients. However, there is also clearly scope for improving the rate of long term use and consideration now needs to be given to more precise clinical criteria, including the relevance of fitness levels required of patients prior to commencement of the treatment system.

\section{Acknowledgements}

The assistance of Christine Hodnett, Lynn Painter, Helen Edmunds and Nicky Thompson in collecting the data is gratefully acknowledged.

\section{References}

HAHN RH 1974 Lower extremity bracing in paraplegics with usage follow-up. Paraplegia 8:147-153.

MIKelBeRg R, REID S 1981 Spinal cord lesions and lower extremity bracing: an overview and followup study. Paraplegia 19:379-385.

NENE AV, PATRICK JH 1989 Energy cost of paraplegic locomotion with the ORLAU ParaWalker. Paraplegia 27:5-18.

ORLAU 1986 Clinical supply of the ParaWalker. ORLAU Annual Report 12:7-9.

RosE GK 1979 The principles and practice of hip guidance articulations. Prosthetics $\mathcal{E}$ Orthotics International 3:37-43.

Rosman N, SPIRA E 1974 Paraplegic use of walking bracing, a survey. Archives of Physical Medicine Rehabilitation 55:310-314.

Stallard J, Major Re, Poiner, R, FARMer IR, Jones N 1986 Engineering design considerations of the ORLAU ParaWalker and FES hybrid system. Engineering in Medicine 15:123-129.

Summers BN, McClelland MR, El MaSRI WS 1988 A clinical review of the adult hip guidance orthosis (ParaWalker) in traumatic paraplegics. Parplegia 26:19-26. 